\title{
Management Transition to Big Data Analytics: Exploratory Study on Airline Industry
}

\author{
Filomena Izzo ${ }^{1}$ \\ ${ }^{1}$ Assistant Professor in Management, Economics Department, Università degli Studi della Campania "Luigi \\ Vanvitelli”, Capua (CE), Italy \\ Correspondence: Filomena Izzo, Assistant Professor in Management, Economics Department, Università degli \\ Studi della Campania "Luigi Vanvitelli”, Capua (CE), Italy.
}

Received: August 2, 2019

doi:10.5539/ibr.v12n10p48
Accepted: September 9, 2019

Online Published: September 16, 2019

URL: https://doi.org/10.5539/ibr.v12n10p48

\begin{abstract}
This paper is addressed to the managers in field of Management Transition to Big Data Analytics, and those who guide and teach them. The research question is following: what is the Transition Management Model to Big Data Analytics in Airline Industry? The reason to choice Airline Industry is attributed to the strategic role that this sector has for the industrial development of a Country. There are few studies on Management Transition to Big Data Analytics and more less in Airline Industry, the present study attempts to contribute to the discussion on this topic.
\end{abstract}

Keywords: big data, data management model, data management transition, airline industry, Airbus' Skywise data platform

\section{Introduction}

Over the last decades, a continuous process of development based on digital technologies has been involving the whole society by leading to the spread of a digital economy (ITMedia Consulting-ASK Bocconi, 2018; Raguseo, 2018; Izzo et al., 2018; Gandomi and Haider, 2015; Diebold, 2012, 2018; Kambatla et al., 2014). We are at the beginning of the Industry 4.0 revolution, is based on the assimilation of physical and digital processes, from the use of information in support of the factories' activities to the optimization in the execution of operating processes (Valerdi, 2017; Al-Barznji and Atanassov, 2017; Singh and Reddy, 2014).

There are immeasurable data generated and shared by private, public and scientific sectors. These data cover textual content (they could be structured, semistructured and unstructured), multimedia content (e.g. videos, images, audio) on several platforms (e.g. cloud computing, Internet of Things, artificial/augmented intelligence, social media sites). Dobre and Xhafa (2014) point out that every day the world makes around 2.5 quintillion bytes of data, and 90\% of these are unstructured. Gantz and Reinsel (2012) report that by 2020, over 40 trillion gigabytes of data will be produced and consumed. "With this overwhelming amount of complex and heterogeneous data pouring from any-where, any-time, and any-device, there is undeniably an era of Big Data-a phenomenon also referred to as The Data Deluge" (Sivarajah et al., 2017: 263).

Data Era is based on high volume, variety, velocity, veracity and variability (Valerdi, 2017). However even more important than the data themselves, it is the ability to draw value from their analysis (Johnson et al., 2017). On this point, since 2013, the European Commission has identified the Value Chain as the key point of the future "economy of knowledge". In fact, many opportunities emerge from the possibility to steadily acquire, structure and assess a great amount of data in terms of knowledge generation, decision making and forecasting (Frisk and Bannister, 2017; Xu et al., 2016; Cai and Zhu, 2015; Landset et al., 2015; Tankard, 2012). Moreover, Big Data are useful, when they lead to business knowledge, that can guide the managerial practice in order to achieve a sustainable competitive advantage (Nambisan et al., 2017; Sumbal et al., 2017; Chen et al., 2014). The strength of Big Data is supported by the Gartner's Top 10 Critical Tech Trends (Savitz, 2012a,b).

In Aviation Industry, insights from Big Data is useful to both manufacturers and to airline companies. About the advantages of manufacturers are included Engineering, Supply chain, Aftermarket, and Program Management. And for airlines ones are refered to Flight Operations, Fleet Management, Maintenance, Inventory Management, Pilot and Crew Management. Future airlines will be able to distinguish themselves from competition and stay at 
the top of the market by their ability to stock and manage big quantities of data both from inside and outside (Sumathi et. al., 2017).

"With the data provided by the newest aircraft, fuel consumption, crew deployment, and flight operations could be optimized to account for varying conditions; maintenance could anticipate when parts need replacing; air congestion could be reduced; flight routes could be altered well in advance of takeoff to avoid storms; systems could back up pilots by handling routine cockpit tasks; and passengers could be kept informed about schedules and options from the minute they leave their home for the airport. It would make the planes easier to fly and maintain and more efficient. It also may reduce crew fatigue with more precise scheduling to help fill in the gaps from anticipated pilot shortages. Ultimately, the data could help with the next iteration of aircraft and systems by providing information about how their design and manufacture could be improved" (Oliver Wyman, 2017: 1).

However, Airline Industry does not seem able to fully exploit data information for lack of technological skills and infrastructure of companies. In fact, recent studies (Oliver Wyman, 2017, 2016) show that the major obstacles to use of Big Data Analytics in Aviation Industry are the lack of time, resources, skills, tools and systems needed to derive value from the data. Our study try to understand better this topic, and we pose following research question: what is the Transition Management Model to Big Data Analytics in Airline Industry?

The reason to study Airline Industry is due the strategic role that this sector has for the industrial development of a Country. There are few studies on Management Transition to Big Data Analytics, and lesser on Airline Industry, the present study tries to contribute to the debate on this topic.

The paper proceeds in following sections. Next section introduces the literature review on Transition Management Model to Big Data Analytics, and then the methodology. Later, the results are showed. Finally, discussion, conclusion and futures research direction are provided.

\section{Literature Review: Management Transition to Big Data Analytics}

As Ardito et al. (2018) show the main theoretical contributions on "Management Transition to Big Data Analytics" topic are: McAfee and Brynjolfsson (2012), Manyika et al. (2011), Barton and Court (2012); Chen et al. (2012), George et al. (2014); Davenport and Harris (2007), Davenport and Patil (2012).

McAfee and Brynjolfsson (2012) explored how Big Data \& Analytics could increase the business performance, by changing the business culture in a data driven culture. By following this approach an important element is having a management that runs the change through: 1) a clear vision of the aims; 2) involving Data Scientist with a proper knowledge of the business where the company works; 3 ) paying attention to the necessary technologies; 4) promoting a collaborative environment among the different company business units; it will allow the company to change into a business supported in its decisional choices from the data and the related analysis. Therefore, McAfee and Brynjolfsson (2012) underline the starting using of the Big Data, huge economic investment aren't fundamental, rather than an approach, which involves different company area.

Also Barton and Court (2012) show that in order to manage transition to Big Data analytics, it is necessary develop a culture data, based on an integrated approach of data sourcing, models elaboration and organizational transformations, without the necessity of embark on titanic revision of technologies. Moreover, a manager must rarely start from data, but rather from the identification of the business opportunities and later to establish how data can improve the company performance.

In order to obtain a data changing, according to Barton and Court, is necessary to develop Analytics which are useful for the company, and they can be used in a simple way, and be included in the processes and actions, which bring to the everyday decisions. Finally, it is necessary to update the competencies.

According to Manyika et al. (2011) the Analytics have the potential to transform the path, which the companies go through to organize, work and manage the talents and create value. In order to this, Manyika et al. proposed 8 actions, specified below.

1. Posing right questions. First of all, each company must pose the right questions according to its own priorities and with extreme clarity; asking themselves in a vague way "which patterns show the data?" can cause a waste of time and resources; some example of most useful questions are "how can we reduce the costs (or increase the income)"? or "how can we increase the productivity of each component of our single team of work?".

2. Thinking small. A significant impact of Big Data Analytics comes from thousands of small improvements. 
3. Paying attention to the taboo. The team of analysis often ignores the suggestions coming from the data that it consider imperfect because of the poor quality or because they are incoherent or dated.

4. Making connections. The company must consider also the information, that can derive from the link among more sets of data, and go thought each internal silos' companies.

5. Acting according to a "continuous cycle" decisional model: observe, orient, decide and act. Google represents a good example of company, which adopts this approach, by taking decisions founded on the analysis of the collected data, and by later quickly incorporating the feedback from analytics in new solutions, and by proposing new products of success.

6. Making the analysis output usable. Companies often employ professional figures with strong analysis competencies more than of results presentation. Obviously the technical competence is a necessary requirement, which is to be supported by the capacity of formulating in a clear way and pleasant results, in order to have the manager not considering them too complicated (and consequently, he could not use them). Furthermore, an interface user-friendly is appreciated by all the employees of the company, which take advantage from the Analytics.

7. Building a team with the multiple and different competences. The Analytics are a team sport, where the key members are the Data Scientists, who help to develop and apply complex analytical methods. As well as there are other specialists such as engineering and cloud and data architects, also developers of user interfaces and creative designers, who grant that the analysis output is usable and pleasant, and an intermediate figures, who connect the Analytics with the business.

8. Let that the outputs of analysis are used. Big Data Analytics do not end in themselves, but they have to be incorporated in one of the operative models, and in the daily flow of work of the company.

The best daily indicator to evaluate an Analytics program, is not the quality of the available data, neither the level of competences of the employee, but the responsibility of the business management, making sure that the insights coming out from the data analysis are actually used. The real aim, is not the adoption of an advanced analysis system but to make sure that it serves the company.

Also George et al. (2014), Davenport and Patil (2012), Chen et al. (2012), Davenport and Harris (2007) observe that for a company, the true challenge is not in the availability of data, but in the capacity to read the data and to have an immediate reaction, to avoid the late correction. They point out that a company wants manage the transition to Big Data analytics requires a gradual adoption of processes, and needs competence, data culture and data governance.

Based on literature study we advance the following propositions about Management Transition to Big Data Analytics:

P1. Each company should leave from the analysis (a real diagnostics) and the identification of the lever on which to act in order to improve its performance; later it should pass to the planning technological progresses.

P2. After a "diagnostics" phase the company should implement the project of digital innovation. The implementation should happen through an agile approach in order to sharpen, and test new solutions in a short period, with the involvement of the whole organization, in order to have everyone understand the benefits brought by the innovation and acquire the adequate competencies for an effective use of the means.

P3. In Management Transition to Big Data Analytics, the key role was played by the top management, which must support the process of transformation of the company, in a way that all organization is interested and innovations are incorporated into daily procedures, with the agreement of all company's employee.

P4. In order to take benefits (in terms of competitive advantage) from the data driven innovation, it needs new company procedures, which invest both the strategic, technological, and governance aspects.

\section{Methodology}

In order to answer our research question we conducted an exploratory study (Miles and Huberman, 1994; Yin, 2009) on Airline Industry, with focus on Airbus Skywise Platform.

The data collected are based on a desk search, with a collection of mainly online information: Aerospace Technology report, Market Line data base, companies web site (e.g. Airbus, Skywise Platform, United Airlines, Delta Airline, Finnair, Latam Airline, Go Air, Sri Lankan Airlines, EasyJet, Emirates, Etihad Airways, Cebu 
Pacific, Allegiant Air, Pegasus Airlines, Philippine Airlines), specialised web site (e.g. China.org.cn, Aviator, Air Transport World).

In accordance with our research goal, and based on Boston Consulting Group approach $(2013$, 2017) we analyses following aspect:

1. Data Vision. These capabilities are crucial in determing the role data and analytics play in a company's business model and strategy and the impact on value creation.

2. Data Usage. These skills enable a company to generate and evaluate idea for using data.

3. Data Engine. These capabilities center around the structures - personnel, proceed and technology - that enable a company to collect, store, mange and use data.

4. Data Ecosystem. These skills are tapped to create partnership and other external relationship that play a role in big data business models and strategies.

\section{Results}

For long time, Airline Industry has a large amount of data, but does not seem able to fully exploit the data information because of lack of technological skills and infrastructure (Sumathi et al., 2017).

As emerges from a recent survey by Accenture (2016), for the aviation companies (Original Equipment Manufacturers and airline companies) data Analytics have become a priority, having understood that the information, that can be drawn from Big Data, can become useful strategies to increase competitive advantage.

In particular, Analytics can bring important competitive advantages both for Original Equipment Manufacturers and for airlines, bringing benefits in engineering, after-sales, the entire supply chain, and project management activities (Bruno, 2017).

Recent studies (Oliver Wyman, 2017, 2016) show that the major obstacles to adopt Big Data in Airline Industry are the lack of time, resources, skills, tools, technology infrastructures and systems required to derive value from the data.

It is in this point of weakness of Airline Industry fits Airbus offer with Skywise Data Platform.

Airbus is a manufacturer of aerospace and defense products and related services. The company offers commercial aircraft, passenger aircraft, corporate jets military aircraft, space systems, space exploration systems, earth observations systems, navigation systems, orbital systems, telecom satellites and unmanned aerial systems (UAS). It has180 international locations and 12,000 direct suppliers (Airbus, 2019a).

"Airbus has launched a new aviation data platform - Skywise - in collaboration with Palantir Technologies pioneers in big-data integration and advanced analytics. Skywise aims to become the single platform of reference used by all major aviation players to improve their operational performance and business results and to support their own digital transformation" (Airbus, 2017:1).

Skywise data platform developed and used by Airbus has seen great success in the analysis and prediction of failures (Neugebauer, 2018). The subsequent increase in safety and operational efficiency is imperative in the progression of such cyber-physical systems, as a key differentiator in effective operations management (Zhou, Fu, \& Yang, 2016).

Adopting Skywise data platform, each users with one access point to cloud-based platform Skywise, have the opportunity to enrich their company data, by bringing together own data to Airline Industry data. These airline industry data include "work orders; spares consumption; components data; aircraft/fleet configuration; on-board sensor data; and flight schedules" (Airbus, 2017:1).

Skywise could help airline companies creating value in more key areas as: "reducing flight disruptions; decreasing maintenance cost through predictive maintenance; optimising flight operations; transforming cabin and ground operations; making faster decisions to cope with unexpected events; and optimising fleet management by interpreting high volumes of fleet and flight operations data [...] This resulting value will soon give Airbus' customers new insights at aircraft, fleet, company, and global level" (Airbus, 2017:1). "Skywise aims to become the platform of reference used by all major aviation players to improve their operational performance and business results and to support their own digital transformation" (Airbus, 2018a:1).

Skywise allows airlines to integrate their operational, maintenance, and aircraft data into a secure and open platform; they can store, access, manage, and analyse own data with selected Airbus data and global airline benchmark data without the need of extra infrastructure investments. Moreover, the technology driving Skywise Platform is created to work with customers' existing IT infrastructures. So they don't need additional investment 
in Data Engine.

Today, numerous major airlines around the world - United Airlines, Delta Airline, Finnair, Latam Airline, Go Air, Sri Lankan Airlines, EasyJet, Emirates, Etihad Airways, Cebu Pacific, Allegiant Air, Pegasus Airlines, Philippine Airlines, WOW Air, Japan Airlines, Bangkok Airways, All Nippon Airways, LATAM, Peach Aviation, Spring Airlines, Air Asia (Airbus, 2019c), - adopted Skywise Platform.

They adopt Airbus Data Platform for: "events tracking and resolution; turnaround-time analysis; operations analytics; predictive maintenance; reliability analysis and benchmarking; maintenance decision support" (Airbus, 2019c:1). Following we report some testimonials by companies that have adopted Skywise Platform.

United Airlines vice-president Praveen Sharma said: "We are proud to partner with Airbus and Palantir on this new data platform, which will allow us to maximise the performance of our Airbus fleet by analysing the best data we have available and using those insights to continuously improve our operation." (Aerospace Technology, 2019:1).

Delta VP-engineering and quality assurance Gary Hammes said "This is another tool to improve the overall reliability of the air-craft and customer experience. This platform will put us another step in front of the competition in predictive maintenance and safety of operations" (ATW, 2019:29).

Finnair head of compliance and operations development Matti Kart- tunen affirmed that Finnair adopted Skywise "to gain insights on aircraft maintenance as well as give aid on analyzing aircraft health" (ATW, 2019:29).

Ignacio Pardo Holtheuer, Manager, digital Transformation at LATAM said "with Skywise we improved a lot of operational reliability [...] we reduced the fraction of mechanical issues leading to delays by $10 \%$. [...] I like the most Skywise [...] there are two thinks. The first one we have basic skills which work in Skywise, that is not coming in other solution, that you can see on the market. In our organization we solved $90 \%$ of the cases with basic users, so this is a huge value for us. And the second, it is very easy to connect different data sources, and it is very flexible, when we work on it. [...] We love Skywise"

(https://skywise.airbus.com/en/success-stories.html\#medialist_copy_11469-video-video-all_ml_0-1).

Mr. Jeh Wadia MD and Acting CEO of GoAir (India) said ""With the growth of our A320 fleet, we are delighted to join Skywise. We are convinced this digital platform will support our daily operations," (Airbus, Press Release, 2019a:1).

Capt. Rajind Ranatunga, Sri Lankan Airlines Chief Officer Service Delivery said "We are confident that Sri Lankan Airlines will benefit from Skywise within our current digital transformation" (Airbus, Press Release, 2019a:1).

Carolyn McCall, CEO of EasyJet, commented: "Over two years our engineers and IT team have been working very closely with Airbus to build the capability to capture the data created by the aircraft systems to try and help minimise and prevent delays. Through this work we have managed to identify the most frequent 100 aircraft faults that cause disruption to our passengers and have been working out how to use the data to detect these faults as they develop" (Aviator, 2017:1).

Emirates Engineering SVP Ahmed Safa said "With Skywise Platform we improved our operational reliability by 1\% during eight months in 2017." (ATW, 2019:29).

Olaf Ploog, Head of Fleet Management at Etihad Airways said "Skywise help us to transform data in to useful information and knowledge, and finally making decision in technical operations of fleets. [...] It is easy to adapt and powerful in its use. [...] We use Skywise in predictive maintenanace". (https://skywise.airbus.com/en/success-stories.html\#medialist_copy_11469-video-video-all_ml_0-2)

Frances Torres, Director Operations Support at Cebu Pacific affirmed "[...] Skywise helped us to get higher insight and understanding into our business, both on the maintenance side and on the operational side. (https://skywise.airbus.com/en/success-stories.html\#medialist_copy_11469-video-video-all_ml_0-3)

Travis Yost, Director MX Ops Planning \& Analytics at Allegiant Air said “[...] Skywise helped us to reduce airline delays, cancellations and AOG scenarios (https://skywise.airbus.com/en/success-stories.html\#medialist_copy_copy_-video-video-all_ml_1-1)

Haluk Demirok, Maintennace Programs \& Reability Leader at Pegasus Airlines affirmed "[...] Skywise give us the opportunity to handle all the platforms in one single point. [...] We wish Skywise to keep it simple thinks: simple, access from everywhere, and we want to knowledge share " (https://skywise.airbus.com/en/success-stories.html\#medialist_copy_copy_-video-video-all_ml_1-2 9 ). Firat 
Uysalol, Project Development \& Proccess Engineer at Pegasus Airlines said "[...] Skywise help us to became a digital airline" (https://skywise.airbus.com/en/success-stories.html\#medialist_copy_copy_-video-video-all_ml_1-29)

\section{Discussion}

Analytics can bring important competitive advantages in both fields: the Original Equipment Manufacturers (Airbus) and the airlines, bringing benefits in engineering, after-sales, the entire supply chain, and project management activities.

In particular, in Airline Industry insights from Big Data is useful to flight operations, fleet management, maintenance, inventory management, pilot and crew management. Airlines will be able to distinguish themselves from competition and stay at the top of the market by their ability to collect and manage big quantities of data both from inside and outside.

As highlighted, Airline Industry does not seem able to fully exploit the information for lack of technological skills and infrastructure. In fact, we found that the major obstacles to use of Big Data Analitics in Airline Industry are the lack of time, resources, skills, tools and systems needed to derive value from the data. In this point of weakness of Airline Industry fits Airbus offer with Skywise Platform.

Airbus Skywise Platform bringing together the different actors of the Aviation Industry breaking the silos within and outside each organisation in order to manage transition to Big Data Analytics leveraging on sharing information.

These data (e.g. flight schedules, work orders, components data, spares consumption, aircraft/fleet configuration, on-board sensor data) enable users to improve many function, as such as predictive and preventative maintenance, operational efficiency, aircraft performance, reporting for regulatory bodies.

From the company testimonials and the information gathered, it clearly emerges that airlines, who have adopted Skywise, have a clear Data Vision and Usage, they are aware of the strategic role that Big Data \& Analytics play in own company's business model, and strategy and the impact on value creation.

Moreover, Skywise Platform is easy to use, it can be adopted with basic users, so with existing companies' Data Engine; in fact, airline companies don't need additional investment in technology infrastructure to gain insight from big data.

Finally, with Skywise Platform every airlines create a directly partnership with Airbus and indirectly with airline industry system (Data Ecosystem); in fact, each users with one access point to cloud-based platform Skywise, have the opportunity to enrich their company data, by bringing together own data to airline industry data.

This opens up new challenges for the field of Airline Industry, and in general for Industrial Engineering, these emerging trends is "Platform Economy" to lead this Big Data technological revolution.

According with recent study (Zutshi and Grilo, 2019; Bettoni et al., 2018) the rising of Digital Platforms is changing every sector of the economy; more Industries, as well as Industrial Engineering, are adopting platforms to manage business, find new partners, manage quality as well as improve performance of marketing and customer support functions.

\section{Conclusion}

The study shows that, for the Airline Industry, the biggest obstacles to implement Big Data Analytics are: lack of resources, skills, tools, and systems needed to extract value from data. These problems can partly be solved thanks to the Skywise Data Platform, offered by Airbus.

In fact, airlines adopting "Skywise can integrate their own operational, maintenance, and aircraft data into one secure and open cloud; wherein they can stock up, access, manage, and analyse selected Airbus data together with their own data and global benchmarks without the need for additional infrastructure investments. Moreover, airlines that agree to share operating data from their Airbus fleet can access the platform at no cost" (Airbus, 2018a:1). Skywise give airlines important competitive advantages, bringing benefits in engineering, after-sales, the entire supply chain, and project management activities.

So, Skywise allows companies to it allows airlines to overcome their economic, knowledge, skills, tools and system barriers to manage the transition to Big Data Analytics. It is emerging new trend called "Platform Economy" which makes easier Management Transition to Big Data Analytics.

Industry Platforms gives many research option, for example we see two platform research questions, that could help us better understanding innovation strategy, and management of technological change. First, we could better 
understand the link between emergence of platform leadership and evolution of business ecosystem. Second, how industry platform focus the attention of innovators on peculiar path of technological change.

The results of our research should be supported by interviews with the companies (for example United Airlines, Delta Airline, Finnair, Latam Airline, Go Air, Sri Lankan Airlines, EasyJet, Emirates, Etihad Airways, Cebu Pacific, Allegiant Air, Pegasus Airlines) that have joined Skywise Platform, in order to better understand the Transition Management Model to Big Data Analytics.

Another aspect that could be analyzed is Data Transition Management Model in Aviation Supply Chain, focused on small and medium enterprises.

Finally, future research could explore the relationship among big data, academic/research ecosystem and supply chain management.

The hope is that this paper will initiate a productive debate and promote researchers to conduct studies about the Big Data Transition Management Model.

\section{References}

Accenture. (2016). Make Your Digital Connection: From Digital Strategy to Airline Strategy. Retrieved from www.accenture.com

Aerospace Technology. (2018). PAL and Airbus sign maintenance deal for A350-900 aircraft. Retrieved from https://www.aerospace-technology.com/news/pal-airbus-sign-maintenance-deal-a350-900-aircraft/

Aerospace Technology. (2019). United Airlines and Airbus to manage data and predictive maintenance. Retrieved from https://www.aerospace-technology.com/news/united-airlines-airbus-aircraft-data/

Air Transport World (ATW). (2019). Tools of the trade. OEMs and airlines tap into software systems that enhance operations. February 2019. Retrieved from Atwonline.com

Airbus. (2017). Airbus launches Skywise-aviation's open data platform. Retrieved from https://www.airbus.com/newsroom/press-releases/en/2017/06/airbus-launches-new-open-aviation-data-platf orm--skywise--to-sup.html

Airbus. (2018a). Airbus' open aviation data platform Skywise continues to gain market traction. February $7^{\text {th }}$, 2018, Retrieved from www.airbus.com

Airbus. (2019a). Company profile.

Airbus. (2019b). Go Air and Sri Lankan Airlines opt for Skywise by Airbus. Retrieved from https://skywise.airbus.com/en/news-and-events/press-releases/2019/02/go-air-and-sri-lankan-airlines-opt-fo r-skywise-by-airbus.html\#media-list-document-document-all_ml_0

Airbus. (2019c). Skywise community expands. Retrieved from https://www.airbus.com/newsroom/news/en/2019/04/skywise-community-expands.html

Al-Barznji, K., \& Atanassov, A. (2017). Review of big data and big data mining for adding big value to enterprises. Science, Engineering \& Education, 2(1), 50-57.

Ardito, L., Scuotto, V., Del Giudice, M., \& Messeni, P. A. (2018). A bibliometric analysis of research on Big Data analytics for business and management. Management Decision. https://doi.org/10.1108/MD-07-2018-0754

Aviator. (2017). EasyJet deploys Airbus Skywise platform for gains in predictive. Retrieved from https://newsroom.aviator.aero/easyjet-deploys-airbus-skywise-platform-for-gains-in-predictive/

Barton, D., \& Court, D. (2012). Making Advanced Analytics Work for You. Harvard Business Review, October 2012, 1-7.

Bettoni, A., Barni, A., Sorlini, M., Menato, S., Giorgetti, P., \& Landolfi, G. (2018). Multi-Sided Digital Manufacturing Platform Supporting Exchange of Unused Company Potential. In 2018 IEEE International Conference on Engineering, Technology and Innovation (ICE/ITMC) (pp. 1-9). https://doi.org/10.1109/ICE.2018.8436294

Boston Consulting Group. (2013). Using Data to Transform Business Models. Retrieved from www.bcg.com

Boston Consulting Group. (2017). Are You Set Up to Achieve Your Big Data Vision?

Bruno, M. (2017). Big Data Commands Big Attention in Aerospace and Defense. Aviation Week \& Space Technology. May $5^{\text {th }}, 2017$. 
Cai, L., \& Zhu, Y. (2015). The challenges of data quality and data quality assessment in the Big Data era. Data Science Journal, 14(2), 1-10. https://doi.org/10.5334/dsj-2015-002

Chen, H., Chiang, R. H. L., \& Storvey, V. (2012). Business intelligence and analytics from Big Data to big impact. MIS Quarterly, 36(4), 1165-1188. https://doi.org/10.2307/41703503

Chen, M., Mao, S., \& Liu, Y. (2014). Big Data: a survey. Mobile Networks and Applications, 19(2), 171-209. https://doi.org/10.1007/s11036-013-0489-0

China.org.cn (2019). China's largest low-cost carrier to use Airbus Skywise data platform. Retrieved from http://www.china.org.cn/business/2019-02/19/content_74479397.htm

Davenport, T. H., \& Harris, J. G. (2007). Competing on Analytics: The New Science of Winning. Harvard Business School Press, Boston, MA.

Davenport, T. H., \& Patil, D. J. (2012). Data scientist: the sexiest job on the 21st century. Harvard Business Review, 90, 70-76.

Diebold, F. X. (2012, 2018). The Origin(s) and Development of "Big Data": The Phenomenon, the Term, and the Discipline (Manuscript), Department of Economics, University of Pennsylvania. 2012, revised 2018. https://doi.org/10.2139/ssrn.2202843

Dobre, C., \& Xhafa, F. (2014). Intelligent sendees for big data science. Future Generation Computer Systems, 37, 267-281. https://doi.org/10.1016/j.future.2013.07.014

European Commission DG Connect. (2013). A European strategy on the data value chain.

Frisk, J. E., \& Bannister, F. (2017). Improving the use of analytics and Big Data by changing the decision-making culture: a design approach. Management Decision, 55(10), 2074-2088. https://doi.org/10.1108/MD-07-2016-0460

Gandomi, A., \& Haider, M. (2015). Beyond the hype: Big data concepts, methods, and analytics. International Journal of Information Management, 35(2), 137-144. https://doi.org/10.1016/j.ijinfomgt.2014.10.007

Gantz, J., \& Reinsel, D. (2012). The Digital Universe in 2020: Big data, bigger digital shadows, and biggest growth in the Far East. IDC-EMC Corporation. Retrieved from http://www.emc.com/collateral/analyst-reports/idc-the-digital-universe-in-2020.pdf

George, G., Haas, M. R., \& Pentland, A. (2014). Big Data and management. Academy of Management Journal, 57(2), 321-326. https://doi.org/10.5465/amj.2014.4002

ITMedia Consulting-ASK Bocconi. (2018). L'economia dei dati. Tendenze di mercato e prospettive di policy. Roma, Gennaio 2018.

Izzo, F., Graziano, D., \& Mustilli, M. (2018). Big data governance e PMI: evidenze dal distretto aerospaziale campano. Sinergie Annual Conference, Florence, Italy.

Johnson, J., Denning, P., Sousa-Rodriguez, D., \& Delic, K. A. (2017). Big Data, Digitization, and Social Change. Ubiquity, December 2017, 1-8. https://doi.org/10.1145/3158335

Kambatla, K., Kollias, G., Kumar, V., \& Grama, A. (2014). Trends in Big Data analytics. Journal of Parallel and Distributed Computing, 74(7), 2561-2573. https://doi.org/10.1016/j.jpdc.2014.01.003

Landset, S., Khoshgoftaar, T. M., Richter, A. N., \& Hasanin, T. (2015). A survey of open source tools for machine learning with Big Data in the Hadoop ecosystem. Journal of Big Data, 2(1), 24-49. https://doi.org/10.1186/s40537-015-0032-1

Manyika, J., Chui, M., Brown, B., Bughin, J., Dobbs, R., Roxburgh, C., \& Byers, A. (2011). Big Data: the next frontier for innovation, competition, and productivity. McKinsey Global Institute. Retrieved from https://www.mckinsey.com/ /media/McKinsey/Business\%20Functions/McKinsey\%20Digital/Our\%20Insig hts/Big\%20data\%20The\%20next\%20frontier\%20for\%20innovation/MGI_big_data_full_report.ashx

McAfee, A., \& Brynjolfsson, E. (2012). Big Data: The Management Revolution. Harvard Business Review, October 2012, 61-68.

Nambisan, S., Iyytinen, K., Majchrzak, A., \& Song, M. (2017). Digital innovation management: reinventing innovation management research in a digital world. MIS Quarterly, 41(1), 223-238. https://doi.org/10.25300/MISQ/2017/41:1.03

Neugebauer, O. (2018). Efficient implementation of resource-constrained cyberphysical systems using 
multi-core parallelism (Doctoral dissertation). Technical University of Dortmund, Germany.

Oliver, W. (2016). MRO Big Data - A Lion Or A Lamb? Retrieved from https://www.oliverwyman.com/content/dam/oliver-wyman/global/en/2016/apr/NYC-MKT9202-001MRO-S urvey-2016_web.pdf

Oliver, W. (2017). Aviation's Data Science Revolution. Retrieved from https://www.oliverwyman.com/content/dam/oliver-wyman/v2/publications/2017/jun/Aviations_Data_Scien ce_Revolution_The_Connected_Aircraft_Final_web.pdf

Raguseo, E. (2018). Big data technologies: An empirical investigation on their adoption, benefits and risks for companies. International Journal of Information Management, 38, 187-195. https://doi.org/10.1016/j.ijinfomgt.2017.07.008

Savitz, E. (2012a). Gartner: Top 10 strategic technology trends for 2013. Retrieved from http://www.forbes.com/sites/ericsavitz/2012/10/23/gartner-top-10-strategictechnology-rends-for-013/

Savitz, E. (2012b). Gartner: 10 critical tech trends for the next five years. Retrieved from http://www.forbes.com/sites/ericsavitz/2012/10/22/gartner-10-critical-techtrends-for-the-next-five-years/

Singh, D., \& Reddy, C. K. (2014). A survey on platforms for Big Data analytics. Journal of Big Data, 2(1), 8-27. https://doi.org/10.1186/s40537-014-0008-6

Sivarajah, U., Kamal, M. M., Irani, Z., \& Weerakkod, V. (2017). Critical analysis of Big Data challenges and analytical methods. Journal of Business Research, 70, 263-286. https://doi.org/10.1016/j.jbusres.2016.08.001

Sumathi, N., Gokulakrishnan, S, Kaushik, R. S, Muralitharan, R., \& Ch. V. S. Kamal (2017). Application of Big Data Systems to Airline Management. International Journal of Latest Technology in Engineering, Management \& Applied Science (IJLTEMAS), VI(XII), 129-132.

Sumbal, M. S., Tsui, E., \& See-to, E. (2017). Interrelationship between Big Data and knowledge management: an exploratory study in the oil and gas sector. Journal of Knowledge Management, 21(1), 180-196. https://doi.org/10.1108/JKM-07-2016-0262

Tankard, C. (2012). Big Data security. Network Security, 2012(7), 5-8. https://doi.org/10.1016/S1353-4858(12)70063-6

Valerdi, R. (2017). When it's big data and when it's not. ISE Magazine, 49(2), 26.

Xu, Z., Frankwick, G. L., \& Ramirez, E. (2016). Effects of Big Data analytics and traditional marketing analytics on new product success: a knowledge fusion perspective. Journal of Business Research, 69(5), 1562-1566. https://doi.org/10.1016/j.jbusres.2015.10.017

Zhou, K., Fu, C., \& Yang, S. (2016). Big data driven smart energy management: From big data to big insights. Renewable and Sustainable Energy Reviews, 56, 215-225. https://doi.org/10.1016/j.rser.2015.11.050

Zutshi, A., \& Grilo, A. (2019). Developing a Digital Platform Architecture and analyzing its impact on Industrial Engineering, Computers \& Industrial Engineering. https://doi.org/10.1016/j.cie. 2019.07.027

\section{Copyrights}

Copyright for this article is retained by the author(s), with first publication rights granted to the journal.

This is an open-access article distributed under the terms and conditions of the Creative Commons Attribution license (http://creativecommons.org/licenses/by/4.0/). 